\title{
Marshall McLuhan's General Theory of Media (GToM), His Laws of Media; Comparing Three Kinds of Law
}

\section{Robert K. Logan}

Department of Physics (60 St George St, Toronto, ON M5S 1A7 Canada), St. Michael's College and the School of the Environment, University of Toronto

logan@physics.utoronto.ca

\begin{abstract}
We suggest that despite McLuhan's claim not to have a theory of communication that in fact the body of his work does indeed constitute a theory of media and their effects which I have called his General Theory of Media (GToM) that also includes his Laws of Media (LoM). Both McLuhan's GToM and his LoM are described. A comparison is made of three notions of law: i. McLuhan's notion of law as used in his Laws of Media; ii. the notions of the Law in the legal sense and iii. the notion of law as formulated in scientific laws. McLuhan's understanding of media is used to analyze some of the negative effects of social media suggesting that laws need to be formulated to prevent the misuse of social media that are antithetical to democracy and the invasion of the privacy of the individual users of these apps. McLuhan's Laws of Media are then used to provide insights into the nature of scientific laws, the Law in the legal sense and his own Laws of Media.
\end{abstract}

Keywords: Marshall McLuhan; General Theory of Media; Laws of Media; scientific laws, the Law, enhance, obsolesce, retrieve; reverse; media; technology

\section{Introduction}

What is law? In this article I will explore the nature three kinds of law and how they differ:

1. Law in the legal sense as they are formulated by governments to regulate the society that they govern;

2. Scientific laws as formulated by scientists to describe natural phenomena; and

3. Law in the sense that the term is used in Marshall McLuhan's Laws of Media (McLuhan, M. 1975, McLuhan, M. 1977 and McLuhan, M and E. 1988). 


\section{Did Marshall McLuhan Formulate a Theory of Media?}

Whenever provoked, Marshall McLuhan would declare, Look, I don't have a theory of communication. I don't use theories. I just watch what people do, what you do. Or words to that effect. That's the short answer to our question, "What is McLuhan's Theory of Communication (McLuhan, E. 2008)?"

Although McLuhan always claimed not to have a theory as we shall see he had a systematic, even systemic, approach to understanding media and their effects. Towards the end of his career McLuhan (1975 \& 1977) formulated his four Laws of Media (sometimes referred to as the tetrad), which indicate, at least to me, that he had an ambiguous attitude towards theory and was possibly entertaining the idea of a theory of media or communication. After all, he called his Laws of Media "the new science" in the title of his book with his son Eric, Laws of Media: The New Science (McLuhan, M. \& E. 1988).

\section{McLuhan's Laws of Media}

In Laws of Media (1988)... Marshall McLuhan summarized his thinking about technology in a concise tetrad of media effects. The tetrad is an analytical tool for considering the effects on society of any technology/medium, artifact, or idea (put another way: a means of explaining the social processes underlying the adoption of a technology, artifact or idea) by dividing its effects into four categories and displaying them simultaneously. McLuhan designed the tetrad as a pedagogical/analytical tool, offering his laws as questions to be asked of any technology, artifact or idea (Kuskis 2014).

Here is a description of the four Laws of Media (LoM):

Every medium, every technology, every human artifact

1. enhances some human function,

2. obsolesces a previous way of achieving that function, 
3. retrieves something from the past that was obsolesced earlier and

4. when pushed to the limits of its potential reverses or flips into an opposite or complementary form (McLuhan 1975 \&1977, McLuhan M. \& E. 1988).

McLuhan's Laws of Media differ from scientific law and Law in the legal sense in that there are many different ways in which media enhance, obsolesce, retrieve and flip into an opposite or complementary form.

There is one caveat about the term laws in McLuhan's Laws of Media, and that is that LOMs are not strictly scientific laws. This is because a LOM does not make unique predictions as to what is retrieved from the past or what complementary form the technology or medium will flip into. The LOM is more of an exploratory tool or probe that provides insights into the effects of a new medium or technology and its possible evolution, and there is often more than one correct answer to the four questions posed by the LOM. The LOM is a generalization or law in that all media obey the same general pattern of enhancement, obsolescence, retrieval, and flip into a complementary form or forms (Iseri and Logan 20016).

I have argued that if McLuhan was able to formulate his laws of media, there must have been a theoretical basis for that formulation that I have come to call McLuhan's General Theory of Media (GToM). I have taken the liberty to formulate McLuhan's GToM, which I believe consists of the following 10 elements (Logan 2021):

1. probes: McLuhan's probes were the formulation of hypotheses that he felt were worthy of exploration. Unlike most scholars he would publish his probes while still studying them because he felt they contained some element of truth. Unlike the natural sciences he could not test his hypothesis quantitatively so he had to be content with his probes;

2. figure/ground: the key element in McLuhan's General Theory of Media (GToM), was that one cannot understand a figure unless one understands the ground or environment in which it operates; 
3. the medium is the message: a medium has effects independent of its content, the content is the figure but the medium is the ground or the environment;

4. the subliminal nature of ground or environment revealed only by the creation of an antienvironment by an artist or a scientist;

5. the reversal of cause and effect: McLuhan's focus was on the effects of media and he was interested in how effects gave rise to causes such as his notion that the effect of the telegraph was the cause of the telephone;

6. the importance of percept over concept, the human sensorium and media as extensions of man: because of his focus on effects McLuhan studied the effects of media on the perceptions of its users which led to his notion of acoustic and visual space;

7. the division of communication into the oral, written, and electric ages and the notions of acoustic and visual space: oral communication is acoustic because during the oral age all forms of acoustic signals arrived simultaneously which is also the case with the signals transmitted with electric media and hence both the oral age and the electric age are characterized by acoustic space. With written communication the information arrives visually in a linear and sequential way which is the characteristic of visual space;

8. the notion of the global village: information with electric media arrives from all across the globe simultaneously creating a global village;

9. media as environments and media ecology: given the medium is the message; the message of a medium is the environment that the medium creates; media interact with each other and the content of a new medium is some older medium; the study of media therefore requires an ecological approach;

10. the Laws of Media: the effects of media can be described by the four laws of enhancement, obsolescence, retrieval and flip or reversal as described above.

\section{The Nature of McLuhan's Reversal}

McLuhan's General Theory of Media is characterized by reversals. McLuhan's use of probes that he sometimes referred to as half true claiming that a half truth is still a lot of truth was a reversal of the standard procedures of the communication scholars of his day. With his figure/ground analyses he reversed the focus on figures to study the environment in which the 
figure operated. The "medium is the message" is a reversal from the fact that he reversed the study of media from that of the content of a medium to the effect of a medium independent of its content. He focussed on the subliminal effects of media rather than the obvious effects of their content through the creation of anti-environments. He reversed the focus on causes to that on effects and hence reversed the focus on concepts to that on percepts. He showed how the transition from the oral age to the literate age represented a reversal from acoustic space to visual space and that the transition to electric media reversed visual space back to acoustic space. His idea of the Global Village contained the notion that the whole planet reversed into a village. And with the Laws of Media he showed how a human artifact when pushed to its extreme flips or reverses into its opposite or complimentary form. Three years before publishing his first paper on the Laws of Media (McLuhan 1975) he wrote with Barrington Nevitt in Take Today Executive as Dropout (McLuhan and Nevitt 1972, 6), "Every process pushed far enough tends to reverse or

flip suddenly. Chiasmus — the reversal to process caused by increasing its speed, scope or size." He used this idea to formulate the fourth of his four laws of media: "a medium when pushed to the limits of its potential reverses or flips into an opposite or complementary form."

Another reversal of McLuhan's is his notion that all media, all human artifacts have both service and disservice. In a letter to Johnathan Miller in April of 1970 he wrote, "All I am saying is that any product or innovation creates both service and disservice environments which reshape human attitudes (Molinaro, McLuhan, C. \& Toye 1987, 404)." It is the service of technology that one is aware of and hence it is the figure whereas the disservice of technology that is subliminal is the ground. Here is another McLuhan reversal in that a new technology is developed because of the service it provides but unbeknownst to its users it also reverses into some forms of disservice which are subliminal. The disservices of the new technology emerge in the subliminal ground or environment that the new technology creates.

\section{The Reversal of McLuhan's “Media as Extensions of Man” to Humankind as an Extension of Their Digital Media}


In his book Understanding Media: Extensions of Man, McLuhan (1964) suggested that all media, all technologies are merely extensions of our bodies or our psyches. He wrote, "all media are extensions of some human faculty — psychic or physical (McLuhan \& Fiore 1967)." He also wrote, "technologies are merely extensions of ourselves (McLuhan 1967b, 261)." McLuhan wrote about media as extensions of man before the digital revolution of personal computers, the Internet, the World Wide Web, search engines, social media and smartphones. With these digital media, that are all post-McLuhan, a reversal has taken place where the users of digital media have become extension of their media as the data they enter becomes part of the system they are interacting with. The reader should be aware that when McLuhan uses the term 'man' in the subtitle and the text of his book Understanding Media: Extensions of Man back in 1964, he was using the term man in its generic sense of humankind or humanity, as was the practice of the day. I have used the term 'man,' here and elsewhere fully cognizant that it may prove offensive to some, which is not my intent, but to play on the words of McLuhan's title. I have taken McLuhan's term "media as extensions of man" and flipped media and man and modified 'media' so as to be read as 'digital media' to suggest that humankind or 'man' are extensions of their digital media.

The way that humankind or 'man' becomes an extension of today's digital media is that companies such as Facebook and Google captures all of the data their users key into their systems and exploit that data commercially to third parties that then use that data against the better interest of those that provided that original data as described by Shoshana Zuboff (2019) in The Age of Surveillance Capitalism and Douglas Rushkoff (2016) in Throwing Rocks at the Google Bus. Here is how Rushkoff (ibid.) describes how this reversal took place:

With every keystroke and mouse click we make their algorithms learn more about us while simultaneously becoming more complex than we-or anyone - can comprehend. They are getting smarter while we humans are getting relatively, or perhaps absolutely, dumber. Our machines slowly learn how to manipulate us. It's a field now called captology: the study of how computers and interfaces can influence human behavior (ibid., 90-91). 
Digital technology pushes electric technology to its extreme which causes a flip or reversal, namely that media as extensions of man also flips into "man (sic) as extensions of his digital technology." The flip is that in addition to digital media acting as extensions of man's psyche as is the case with oral, written and electric media, it is also the case that 'man' or the users becomes an extension of their digital technology as the data they input into their digital media becomes an extension of those media. Digital media systems consist of three elements: the hardware and software of which they are composed but a third component as well, namely, the data that is stored within them. Much of the big data that sits within them comes directly from their users of the system as every key stroke and choice they make is information that is fed into the system as data as just described by Rushkoff above.

\section{The Threat to Democracy from the Misuse of Surreptitious Data Collection and Social Media}

\section{Social Media:}

Enhance: online connections and non-local friendships; the image of the user of the social media site.

Obsolesce: face-to-face socialization and real life.

Retrieve: long distance correspondence; Narcissus and masquerade.

Reverses: into social isolation; online virtual life and socializing; fake identities and fake news.

If the only use of the capture of information was to target advertising to the users of digital apps this would not be so serious though still unacceptable. However, the data surreptitiously gathered has been used by political operatives to threaten our democratic practices as was the case with the Cambridge Analytica scandal and their use of Facebook that compromised the 2016 USA presidential election and the UK Brexit referendum. By gathering information about users of social media like Facebook political operatives were able to target voters that would be susceptible to their messages and bombarded them with fake information and fake news affecting the outcome of the 2016 presidential vote and the Brexit referendum. 
The Russians also affected these two electoral processes by disseminating fake news on social media.

An even more serious threat to democracy has come from the use of social media by Donald Trump by making use of fake news and lies to promote his agenda of overturning an election he lost to Joe Biden. This included his use of the main stream media and social media to create his Make America Great Again (MAGA) movement and the use of social media that the MAGA movement used to organize itself, its rallies and its attempted coup of the American government. On January 6, 2021 in Washington DC Trump and his agents held a rally in the morning at which Trump incited his followers and members of the MAGA movement to storm the U.S. Capitol and overturn the presidential election that he had just lost. This insurrection and attempted coup d'etat have revealed that the regulation of social media and the dissemination of fake news and lies like Trump's big lie that the election was stolen from him must be regulated by law.

In light of the events that took place on January 6, 2021, namely the insurrection of the Trump supporters that attacked, entered and desecrated the U.S. Capitol in their attempt to overthrow the government and reverse the outcome of the 2020 presidential election we must mention some of the truly ugly and evil disservice aspects of social media. Although the insurrectionists were directly egged on by Trump's rhetoric in an outdoor rally held in the morning of January $6^{\text {th }}$, the MAGA movement that he created and mobilized was a direct result of his use and their use of social media. Twitter served as the medium for his assault on the truth, the tens of thousands of out-right lies and the biggest lie of all that he actually won the 2020 election, that the election was rigged and that it was stolen from him despite the fact that the Republicans actually increased their numbers in the House of Representatives. As pointed out by Timothy Snyder (2017) in his book On Tyranny: Twenty Lessons from the 20th Century, "lies can lead to fascism." Trump and his followers misuse of Twitter is the ugly side of the disservice of social media. And it was not only Twitter but other forms of social media that allowed these enemies of democracy to organize themselves into a movement that has shook the very roots of American democracy.

Hitler made use of radio and the loudspeaker to create his racist Nazi movement. These technologies were relatively new in the 1930's when Hitler undermined Germany's democratic 
government. Social media such as Facebook, Instagram and Twitter are also relatively new technologies that emerged in the past 25 years. It is interesting that Twitter finally realized the harm it created when it finally banned Trump from using Twitter as a way to prevent him from doing any further damage after the January 6 fiasco. But at the time of this writing it has been reported that Trump is planning to start his own Twitter-like app and weaponize social media. Trump is not finished with his misuse of social media which he will use once again to try to overthrow American democracy with lies and fake news.

\section{To Regulate or Not to Regulate}

The story of the January 6th episode, which is not yet over as these words are written, is a cautionary tale. Given the damage that has been wrought serious thought must be given to how social media can be regulated by law in the legal sense. If today's democracies have agencies to regulate public broadcaster such as the Canadian Radio-television and Telecommunications Commission here in Canada, the Federal Communications Commission in the USA and the European Commission in the European Union serious thought must be given to a commission (perhaps an international one) to regulate the operation of social media companies such as Facebook, Instagram and Twitter.

Freedom of speech does not allow one to cry fire in a crowded theatre to cause a stampede. Freedom of speech should not allow social media to allow its users to post antidemocratic, fascist, racist, or other dangerous forms of fake news and incitements to encourage illegal acts. It is easy for us to condemn the posting of such material but the challenge will be how to exactly define what kind of material should be banned and how. Just as the legal system has a judiciary to judge what acts are illegal, a judicial system should be created to determine what material needs to be regulated on social media. I believe that a social media platform that allows messages to be posted that act as incitements to encourage illegal acts should be libel under existing conspiracy laws. Social media should not be allowed to aid and abet illegal actions. It is beyond my expertise to suggest how this social media regulatory system should be organized but it is clear to me in light of my analysis of social media and that of many others that there is a need for such a system. And the events of January 6, 2020 in Washington DC and the 
presidency of Donald J. Trump have made it clear that serious thought needs to be given to this issue and a mechanism to protect democracies from the abuses of social media must be developed.

\section{Three Forms of Law: McLuhan's Laws of Media, Scientific Laws and the Law in the Legal Sense}

There are three forms of law that I would like to compare using McLuhan's Laws of Media. They are:

1. Scientific laws as in Newton's three laws of motion or the three laws of thermodynamics;

2. Laws in the legal sense formulated by human lawmakers in parliaments or parliamentlike bodies to insure order and tranquility.

3. The use of law as the way McLuhan uses the term in his Laws of Media (LoM) tool;

Let us now compare the nature of these three forms of law:

1. Scientific laws make precise predictions that can be confirmed empirically or disproven if they disagree with experiments or new observations. These laws must be falsifiable and are subject to modification if new evidence is uncovered. They are also subject to strict peer review. Science cannot prove that a proposition is true but only that it is consistent with all the observations and experiments made to date (Logan 2003).

2. Laws in the legal sense are subject in a democracy to change by the bodies that formulated them following the constraints of their constitution. In a democracy, the interpretation of the law is subject to the decisions of a constitutionally established judiciary.

3. McLuhan's Laws of Media are probes and hypotheses that do not lead to precise results in that there can be differences of opinion of the persons making use of the LoM tool to probe a medium or human artifact in terms of what it enhances, obsolesces, retrieves and when pushed far enough what it flips or reverses into. 
McLuhan saw a connection to his Laws of Media to Francis Bacon and Giambattista Vico each of whom referred to their work as the "new science." McLuhan and his son Eric used the term in the title of their book Laws of Media: The New Science. The use of the term "the new science" is an acknowledgement of the influence of both Francis Bacon and Giambattista Vico, both of whom talked of their work as the "new science." Eric McLuhan wrote in the preface to the Laws of Media, The New Science:

Vico... targeted 'the modification of our own minds' as the crucial area, while he cast about for a way to read and write the 'mental dictionary.' Then the relationship between [Roger] Bacon's idols and Vivo's axioms surfaced - bias of perception - and the job was near done. Bacon called his book the Novum Organum, The New Science; Vico called his, the Science Nuova, The New Science.

Lorraine Weir (1989) also notes the relationship of McLuhan and Vico, "Both Vico and McLuhan were rhetoricians who in the course of their work of necessity became poets. Both were semioticians more or less manqué." Francesco Guardiani (1996) concurred with Weir, "Like Vico, McLuhan develops his poetics of cognitive/technological process in terms of a neoAristotelian rhetoric of processual mimesis informed by Francis Bacon as much as by Vico, Joyce, and Scholastic theology."

\section{Conclusion: The Application of McLuhan's Laws of Media to the Three Kinds of Law}

In this concluding section we make use of McLuhan's LoM tool to probe the nature of the three forms of law we have identified, namely the Laws of Media itself, scientific law as formulated by scientists based on their observations of nature and the experiments that they conduct and the Law in the legal sense as formulated by governments.

All three forms of laws share something in common. They all are about formulating regularity: the regularity of how citizens should behave in society as formulated by legislators; 
the regularities of the natural world as observed by scientists; and the regularities of the effects and impacts of technology as observed by McLuhan and his co-workers.

\section{McLuhan's Laws of Media:}

Enhance: probing;

Obsolesce: content analysis;

Retrieve: intuition; and

Flip or reverse into: understanding media.

\section{Scientific Laws:}

Enhance: knowledge and an understanding of nature;

Obsolesce: ignorance and superstition;

Retrieve: intuition; and

Flip or reverse into: new technologies.

\section{Legal Laws:}

Enhance: order and tranquility;

Obsolesce: anarchy and abuse of power;

Retrieve: The Garden of Eden; and

Flip or reverse into: oppression when misused

\section{References}

Guardiani, Francesco. 1996. "Laws of Media and the Critics." McLuhan Studies: Premiere Issue (http://projects.chass.utoronto.ca/mcluhan-studies/v1_iss1/1_1index.htm/, accessed March 19, 2021).

Iseri, Zeynep Mervi and Robert K. Logan. 2016. "Laws of Media, Their Environments and Their Users: The Flip of the Artifact, Its Ground and Its Users.” MDPI Philosophies 1(2), 153-161.

Kuskis, Alex. 2014. "The Law of Media - A Conceptual Tool for Understanding Media (https://mcluhangalaxy.wordpress.com/2014/10/10/the-laws-of-media-a-conceptual-tool-forunderstanding-media/, accessed March 21, 2021)." 
Logan, Robert K. 2003. "Science as a Language, the Non-Probativity Theorem and the Complementarity of Complexity and Predictability." In Daniel McArthur \& Cory Mulvihil (eds) Humanity and the Cosmos, Binghampton NY: Global Academic Publishing State University of New York Binghampton, 63-73.

Logan, Robert K. 2021. McLuhan in Reverse. New York: Peter Lang (In press).

McLuhan, Marshall. 1975. "Communication: McLuhan's Laws of Media." Technology and Culture 16 no. $1: 74-78$.

McLuhan, Marshall. 1977. "Laws of Media." English Journal 67 no. 8: 92-94. also published Et Cetera 34 no. 2: 173-179.

McLuhan, Marshall, and Eric McLuhan. 1988. Laws of Media: The New Science. Toronto: University of Toronto Press.

McLuhan, Eric. 2008. "Marshall McLuhan's Theory of Communication: The Yegg.” Global Media Journal 1 (1), 25-43.

Molinaro, Matie, Corrine McLuhan, and William Toye (eds). 1987. Letters of Marshall McLuhan. Toronto: Oxford University Press.

Rushkoff, Douglas. 2016. Throwing Rocks at the Google Bus. New York: Portfolio.

Snyder, Timothy. 2017. On Tyranny: Twenty Lessons from the 20th Century. New York: Tim Duggan Books a subsidiary of Penguin Random House.

Weir, Lorraine. 1989. "Laws of Media: Vico and McLuhan on the New Science" Signature 2, 60-70.

Zuboff, Shoshana. 2019. The Age of Surveillance Capitalism. London: Profile Books. 
